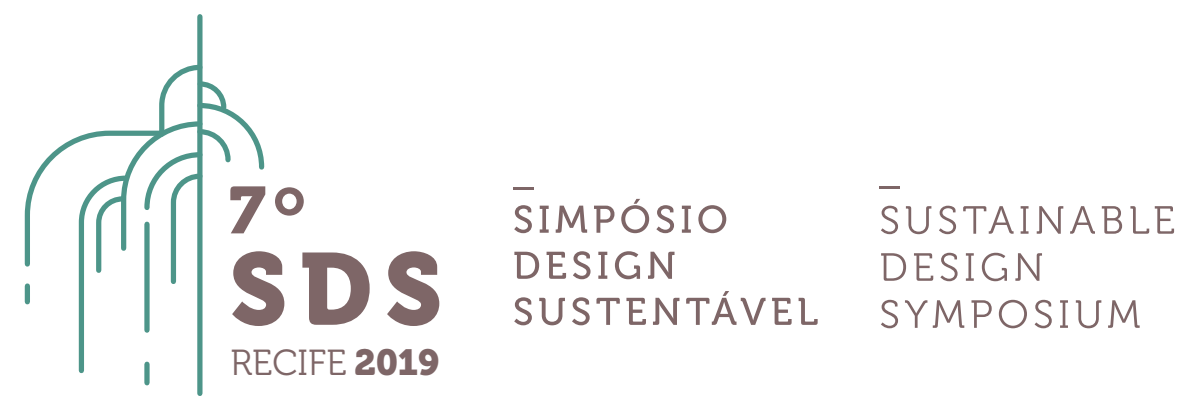

\title{
Contribuições do design estratégico para a educação : um estudo de caso da Escola da Ponte e do Escola Projeto Âncora.
}

\author{
Me. Camila Andrade Scroferneker ${ }^{1}$, and Dra. Karine de Mello Freire ${ }^{2}$ \\ ${ }^{1}$ andrade.camis@gmail.com \\ ${ }^{2}$ Unisinos, Programa de Pós-graduação em Design, kmfreire@unisinos.br
}

\begin{abstract}
Resumo Neste artigo pretendemos refletir sobre como o design estratégico pode contribuir na criação e desenvolvimento de estratégias de semeadura de inovação social, no âmbito da educação. Através do estudo de caso da relação entre a Escola da Ponte e a Escola Projeto Âncora buscamos compreender o processo de disseminação de inovação social entre ambas. Para a realização da nossa pesquisa, fizemos uma imersão de 5 dias em agosto de 2017 na Escola Projeto Âncora. As técnicas utilizadas foram: pesquisa bibliográfica e documental, observação direta e entrevista focalizada com questões semiestruturadas. Após a descrição e interpretação dos dados coletados, identificamos três estratégias de semeadura que, sob a nossa perspectiva de designer estratégico, foram utilizadas para a disseminar sementes de inovação social de um contexto a outro.
\end{abstract}

Palavras-chave. Design Estratégico. Inovação Social. Semeadura. Projeto Âncora.

\section{Introdução}

A revolução das tecnologias da informação e as novas práticas organizacionais originaram uma nova economia - informacional, global e em rede. (CASTELLS, 2009). A necessidade de produzir e compartilhar conhecimento e informação impõe-se, demandando uma outra lógica de inteligência que requer competência na prática dos processos e que deixe a tônica do objeto (computador, software) em direção à tônica do projeto (ambiente cognitivo, rede de relações humanas). Sob essa perspectiva, mudanças socioculturais são necessárias, principalmente voltadas à promoção do conhecimento de forma integrada, que estimule a curiosidade e a criatividade e, fundamentalmente, forme cidadãos autônomos com capacidade crítica. Consideramos que a escola é o local que pode ser ressignificado para lidar com esses desafios. 0 design, além de projetar novos sistemas, pode projetar estratégias para disseminar inovações sociais bem sucedidas. Uma dessas estratégias é a de semeadura - uma forma de espalhar sementes com ideias inovadoras de um contexto para o outro, com intuito de gerar versões adaptadas e em constante desenvolvimento, da referência original. (FREIRE; DEL GAUDIO; 
FRANZATO, 2016). Para entender a viabilidade dessas mudanças no âmbito da educação, definimos como objeto da nossa pesquisa a relação entre a Escola da Ponte (Portugal) e a Escola Projeto Âncora (Brasil), em função da possibilidade de refletir sob a ótica do design as relações que foram (e ainda são) construídas entre ambas, voltadas para a inovação social. As duas escolas têm filosofia diferenciada e buscam reconfigurar a forma de ensinar e aprender. A primeira (Ponte) serviu de inspiração para a segunda (Âncora).

Nosso objetivo, neste artigo, é evidenciar as possíveis contribuições do design estratégico na criação e desenvolvimento de estratégias de semeadura, e consequentemente, na geração de inovação social.

\section{A (Re)Significação da Escola - Caminhos para Inovação Social}

A escola identificada como tradicional ${ }^{a}$ surgiu no século XVIII, durante a Revolução Industrial, no período conhecido como lluminismo. Sua função era qualificar e educar a todos, independentemente de classe social, com o objetivo de formar mão de obra profissional para atuar nas fábricas. Sob esta perspectiva, a organização do espaço escolar através das séries permitiu uma "economia do tempo de aprendizado", atuando como uma "máquina de ensinar". (FOUCAULT, 2010, p. 145). A sala de aula adquire formato homogêneo, com alunos dispostos em fileiras, sob o olhar do professor, cuja ordenação espacial individualiza, classifica e combina os indivíduos dentro de determinado espaço. (FOUCAULT, 201).

Esta homogeneização do sistema educacional privilegia, de forma velada, como apontou Bourdieu e Passeron (2014), quem já é privilegiado, ou seja, quem já domina os códigos necessários para atender às expectativas na vida escolar. Ao partir do pressuposto que todos os indivíduos aprendem e raciocinam do mesmo jeito, que têm as mesmas condições de assimilar os conteúdos e que estes conteúdos são relevantes para ele, a escola apenas reproduz e legitima a desigualdade social. O contexto em que a escola tradicional foi criada é bem diferente do que temos nos dias de hoje. É necessária uma reconfiguração do equilíbrio entre homem, ferramenta (tecnologia) e sociedade, voltada a uma organização democrática, flexível e horizontal, em que os avanços da ciência contribuam para o aumento do poder e saber do indivíduo e do coletivo. (LEVY, 2011).

De acordo com Levy (2011, p. 20), nas últimas décadas do século passado "a economia planificada de forma burocrática [...] foi incapaz de seguir as transformações impostas pela evolução contemporânea das técnicas de organização do trabalho". Para prosperar nesta nova dinâmica, é preciso operar numa lógica de redes (CASTELLS, 2009), estabelecendo laços sociais (LEVY, 2011, p. 26) "que produzam uma inteligência coletiva - distribuída por toda parte, valorizada, coordenada em tempo real, que resulte na mobilização efetiva das competências". (LEVY, 2011, p. 28). Em outras palavras, a prosperidade está na capacidade das pessoas e das organizações movimentarem-se no espaço do saber ${ }^{b}$, da inteligência e do conhecimento coletivo.

\footnotetext{
a O educador brasileiro Paulo Freire, em sua obra Pedagogia do Oprimido, lançada na década de 70, já criticava esta metodologia, que denominava de "educação bancária". (FREIRE, 1987, p. 37). Para o referido autor "A educação se torna um ato de depositar, em que os educandos são os depositários e o educador o depositante [...]"sendo que [...] “a única margem de ação que se oferece aos educandos é a de receberem os depósitos, guardá-los e arquivá-los". (FREIRE, 1987, p. 37).

bLevy (2011) acredita que o espaço do saber não existe na sua essência, mas "submetido às exigências da competitividade e aos cálculos do capital" (LEVY, 2011, p. 122). Este espaço seria um novo horizonte para a civilização. Um espaço livre e autônomo, "habitado, animado por intelectuais coletivos - imaginantes coletivos - em permanente reconfiguração dinâmica” (LEVY, 2011, p. 123), que surge em função da velocidade da evolução dos saberes, da convocação das massas a aprenderem e a produzirem conhecimentos e ao surgimento de novas ferramentas que servem para organizar os fluxos informacionais (LEVY, 2011).
} 
"Tudo repousa, a longo prazo, na flexibilidade e vitalidade de nossas redes de produção, comércio e troca de saberes", afirma Levy (2011, p. 19).

Entre muitos métodos e ferramentas utilizados para potencializar este tipo de mudança, a abordagem do design tem se mostrado bastante eficiente, trazendo clareza e vivacidade para áreas de serviços nos quais sempre os mesmos padrões foram utilizados para solucionar problemas, visto que seus métodos aceleram o pensamento ao incentivar a visualização e prototipação das ideias. (MULGAN, 2014). Ao estimular uma forma diferente de pensar, o design auxilia os indivíduos a enxergarem as questões e as possibilidades sob um novo prisma, despertando a criatividade e facilitando a identificação de possíveis conexões entre as coisas, que tão frequentemente se tornam obscurecidas pela rotina do cotidiano que dominam tanto os governos como as empresas. (MULGAN, 2014).

O design estratégico é uma metodologia de projeto que cria estratégias integradas de produto, serviço e comunicação, que podem ser colocadas em prática por um ator e/ou uma rede de pessoas, com o intuito de desenvolver um conjunto de soluções. Estas estratégias são sistemas de normas, regras e ferramentas, que através da construção de cenários e das ambições dos diferentes atores envolvidos, da investigação entre o real problema e sua possível melhor solução, da inovação social, da colaboração entre os envolvidos e do diálogo estratégico, habilitam órgãos sociais e empresas a lidar com ambientes complexos. (MERONI, 2008). Além disso, o design estratégico pode identificar "ideias promissoras" (FREIRE; DEL GAUDIO; FRANZATO, 2016, p. 642), ao distinguir uma referência positiva e usá-la como inspiração para disseminar novas possibilidades para determinado problema. Isto é, a iniciativa que origina uma mudança de comportamento social e cultural pode ser compreendida como protótipo já existente, sendo capaz de gerar inovação social através da atividade de design estratégico. (MERONI, 2008).

De acordo com Mulgan et al. (2007), o processo de inovação social movimenta-se entre quatro momentos, que não necessariamente ocorrem de forma linear, gradual e ordenada, não obstante necessitem ser pensados numa perspectiva integradora:

- Compreensão das necessidades, geração de ideias e identificação de soluções em potencial;

- Desenvolvimento e prototipação das ideias;

- Avaliação, expansão e difusão das boas ideias;

- Aprendizagem e evolução das ideias.

Para a disseminação de iniciativas de inovação social, Manzini (2008) sugere três tipos de estratégias design: franquia (que possui uma lógica de reprodução rígida de um modelo), format (que usa uma lógica de modelo, com passo a passo) e toolkit (abordagem "faça você mesmo"). Por sua vez, Freire, Del Gaudio e Franzato (2016) acrescentam a estas estratégias a semeadura - uma dinâmica de difusão projetual que busca espalhar sementes com ideias inovadoras de um contexto para o outro, gerando versões adaptadas e em constante desenvolvimento, da referência original. Em outras palavras, a semeadura é uma de estratégia generativa, que orienta, porém não restringe sua aplicação.

O design estratégico emerge para conduzir e auxiliar na disseminação destas sementes, desenvolvendo estratégias da ação projetual no âmbito das relações ecossistêmicas. (FRANZATO et al., 2015). As competências técnicas do design - ver, prever e fazer ver (ZURLO, 2010) - tendem a promover o diálogo entre os diferentes atores envolvidos no processo de semeadura, buscando ambientar iniciativas já existentes em outros contextos, visando mudanças de comportamento e, consequentemente, inovação social. Para ilustrar projetos bem-sucedidos de inovação social Manzini (2017) cita dois casos: o movimento da reforma psiquiátrica (Psiquiatria Democrática), 70 SDS $_{2019}^{\mathrm{RECIFE}}$ 
realizada por Franco Basaglia, e o movimento Slow Food, de Carlo Petrini. O primeiro ocorreu na década de 1970 na Itália, quando Basaglia fechou o hospital psiquiátrico que comandava e decidiu abordar a doença mental sob outro viés - criando grupos de produção, ou seja, serviços compostos por médicos, ex-pacientes, enfermeiros, onde os pacientes pudessem "superar suas dificuldades e desenvolverem suas capacidades". (MANZINI, 2017, p. 74). Já o movimento Slow Food surgiu no final da década de 1980 para fomentar um "sistema de produtos e serviços" (Ibidem, p.75), onde produtores agrícolas locais estabeleciam contato com pessoas que desejavam consumir produtos alimentícios de qualidade (sem agrotóxicos, orgânicos). Tanto Basaglia e quanto Petrini ressignificaram as dinâmicas que estavam envolvidos ao criarem organizações com novos laços relacionais, empoderando os atores participantes. Manzini (2017) ressalta que nenhum dos dois é especialista em design, porém o autor os considera designers de facto (por consequência) e grandes inovadores.

Considerando tais perspectivas, acreditamos que a escola precisa [e pode] inovar, sem necessariamente "criar do zero" possibilidades para viabilizar a inovação, ou seja construir uma educação onde os cidadãos possuam mais autonomia, senso crítico e de colaboração. Há inúmeras alternativas ${ }^{c}$, inclusive no Brasil, que geram bons resultados ao repensar os antigos modelos de ensino, que prosperam e podem servir de referência para inspirar o desenvolvimento de novas iniciativas em diferentes contextos. A Escola da Ponte é um exemplo destas iniciativas, que, desde a sua criação vem inspirando educadores a (re)pensar a educação, como a Escola Projeto Âncora.

\section{Relação Escola da Ponte X Projeto Âncora}

A Escola da Ponte é uma instituição pública situada em São Tomé de Negrelos, no distrito do Porto, em Portugal. Até 1976, tinha estrutura tradicional, com séries, turmas, salas de aula, provas e uma lógica de aprendizagem focada na autoridade do professor. Nas palavras do seu idealizador, José Pacheco (2008, p. 12), a Ponte era "um arquipélago de solidões", onde havia isolamento por parte da comunidade e dos professores, exclusão social, indisciplina, agressões e uma estrutura física sucateada. A partir da problematização da situação e da "interrogação das práticas educativas dominantes" (PACHECO, 2008, p. 13), a equipe definiu alguns objetivos:

\footnotetext{
[...] concretizar uma efetiva diversificação das aprendizagens, tendo por referência uma política de direitos humanos que garantisse as mesmas oportunidades educacionais e de realização pessoal para todos, promover a autonomia, operar transformações nas estruturas de comunicação e intensificar a colaboração entre instituições e agentes educativos". (PACHECO, 2008, p. 12).
}

Com base nestes objetivos, a lógica organizacional da escola foi modificada, isto é, as séries foram abolidas, assim como as turmas, as provas e as salas de aula. A nova estrutura organizacional (organização do espaço, do tempo e da forma de aprender) passou a demandar maior participação das crianças e da equipe no planejamento das atividades, na sua aprendizagem e na avaliação.

Partindo desta lógica, os conteúdos, os quais todos deveriam aprender, continuaram sendo desenvolvidos, porém através de dispositivos que permitissem uma prática individualizada, como por exemplos: tutorias individuais, roteiros de estudos e pesquisas em pequenos grupos, com o mesmo tema de interesse. As séries, turmas e ciclos deram lugar aos núcleos de projeto: iniciação, consolidação e aprofundamento. A passagem de um núcleo para outro está relacionada a um

\footnotetext{
${ }^{3}$ Tais como: A Escola Lumiar em São Paulo, a Riverside School na Índia, a Cidade Escola Ayni, no interior do estado do Rio Grande do Sul.
} 
perfil de transição estabelecido no Projeto Educativo ${ }^{\text {}}$, que promove valores como a autonomia, consciência cívica, a solidariedade e a democracia ${ }^{e}$ incentivando progressivo envolvimento do aluno nas tarefas e na gestão da escola.

Os professores tornaram-se orientadores educativos e passaram a ter uma formação multidisciplinar (psicólogos, pedagogos, terapeutas, entre outros), para contribuir com formação sistêmica e desenvolvimento educacional do aluno, pois este começa a ser visto como o "verdadeiro sujeito do currículo - e não um instrumento ou um mero destinatário do currículo". (SANTOS, 2012 apud ALVES, 2012). As salas de aula tornaram-se espaços de trabalho compostos por recursos de pesquisa (livros, dicionários, computadores). A tomada de decisão coletiva e a interação entre a equipe escolar e os membros da comunidade (inicialmente representada pelos pais dos alunos) passou a ser um imperativo na organização da escola e nos processos de aprendizagem. A auto avaliação se tornou uma prática constante e sistemática no sentido de analisar e refletir sobre os processos de aprendizagens, a ação pedagógica, os resultados escolares e a dinâmica da escola. Uma série de dispositivos foram desenvolvidos para direcionar, apoiar e perpetuar esta transformação cultural.

O Projeto Âncora é uma ONG, localizada na cidade de Cotia em São Paulo, que surgiu em 1995 por iniciativa do empresário Walter Steurer e sua esposa Regina Steurer. Foi concebido, inicialmente, como um espaço para atividades de contra turno para as crianças e cursos profissionalizantes para maiores de 16 anos. Em 2012, entenderam que era o momento de criar uma escola e procuraram o educador José Pacheco, para assessorá-los na concepção de uma escola de ensino infantil e fundamental (e a partir de 2018 de ensino médio) com uma proposta inspirada na Escola da Ponte.

Assim como a Ponte, a Escola Projeto Âncora tem uma nomenclatura própria: alunos são chamados de educandos. As salas de aulas são denominadas de espaço de aprendizagem. Professores são educadores e tutores. Os tutores são pessoas com formação acadêmica, especialistas em alguma disciplina. Já educadores são as pessoas da equipe que compõem a escola (motoristas, cozinheiras, secretária, também os tutores). Acreditamos que esta nomenclatura busca ressignificar o papel dos atores envolvidos nos processos de aprendizagem, através da ideologia materializada pelo discurso (ORLANDI, 2007), de emancipação e autonomia.

Dentre as principais características da Escola Projeto Âncora destacamos a ausência de estrutura seriada, de divisões de turma e provas. A clássica divisão Educação Infantil, Ensino Fundamental e Ensino Médio é substituída por núcleos de aprendizagem denominados Iniciação, Desenvolvimento e Aprofundamento, e em cada uma delas há crianças e adolescentes de todas as idades. A lógica desses núcleos está relacionada à autonomia e à absorção do educando por parte dos pilares $^{f}$ da Escola (afetividade, honestidade, respeito, responsabilidade e solidariedade), e não aos conteúdos das áreas do conhecimento, exigidos pelos Parâmetros Curriculares da Educação Nacional. Estes são contemplados através dos dispositivos da Escola (roteiros de estudo, planejamento, pesquisa). Não há idade para pertencer a determinado núcleo de aprendizagem. Qualquer criança ou adolescente que chega ao Projeto Âncora começa a sua jornada escolar na

\footnotetext{
d Disponível em: <http://www.escoladaponte.pt/novo/wp-content/uploads/2016/11/PE.pdf>. Acesso em: 27 jan. 2018.

e Estes quatro valores são os princípios chaves da Escola da Ponte, que na Escola Projeto Âncora são chamados de pilares.

${ }^{f}$ Segundo a co-fundadora da Escola Projeto Âncora, estes pilares são valores que foram escolhidos através de uma votação pela equipe interna, quando a Escola começou a ser construída dentro da ONG. Percebemos que eles são os valores base, por isso são chamados de pilares, que tendem a permear praticamente todos os processos dos dispositivos. Acreditamos ser oportuno ressaltar que identificamos outros valores presentes durante nossa imersão, como por exemplo a igualdade, sustentabilidade, colaboração, entre outros.
} 
iniciação, independente da série que estava na sua escola de origem.

O ensino segue a lógica de pedagogia por projeto, onde o educando e tutor definem temas de interesse e desenvolvem os conteúdos. Se mais de um educando tem interesse no mesmo assunto, são formados grupos de estudos. Os prazos e as sequências das tarefas também são selecionados em conjunto, assim como a avaliação. Tutor e educando avaliam juntos quando, e se é, o momento de mudar de um núcleo de aprendizagem para outro (da iniciação para o desenvolvimento, por exemplo). Além deste processo de tutoria, os educandos são incentivados a se auxiliarem mutuamente, a participarem das tomadas de decisões por meio de atividades semanais, como assembleias e rodas de reflexão, e a integrarem em atividades que envolvem a comunidade. A Escola acredita que desta forma estará desenvolvendo os educandos na cidadania, ou seja, através de atividades que demonstrem na prática como agir de forma cidadã.

Entendemos que os valores e pressupostos oriundos da filosofia da Escola da Ponte são uma semente de inovação social que foram adaptados e reconfigurados à realidade local da cidade de Cotia. É importante salientar que a Escola Projeto Âncora não foi criada a partir da atividade de design estratégico, entretanto, acreditamos que iniciativas como estas podem ser reconhecidas como design difuso, isto é, o fazer design por não especialistas na área. (MANZINI, 2017). Pacheco e Steurer podem ser considerados designers de facto (Ibidem, 2017), ou seja, por consequência. O primeiro, pela sua capacidade em identificar um problema local, criar, liderar e engajar um grupo de pessoas dispostas a reconfigurar uma escola e desenvolver laços relacionais entre elas. Já o segundo, por sua habilidade em reconhecer e promover uma "ideia promissora" (FREIRE; DEL GAUDIO; FRANZATO, 2016, p. 642). Walter Steurer não apenas percebeu na Escola da Ponte como a semente de uma nova escola, mas também na ONG Projeto Âncora como um terreno fértil para implementação do projeto e no educador José Pacheco como um jardineiro habilidoso, que pudesse, em conjunto, conduzir esse processo. (MANZINI, 2017). Na seção a seguir, apresentaremos este processo de difusão por semeadura.

\section{Difusão de inovação social por processo de semeadura}

Nesta sessão apontaremos os caminhos que o design pode percorrer para projetar estratégias de semeadura. Acreditamos que não existam regras a serem seguidas no processo de disseminação de uma semente de inovação social. Concordamos com Manzini (2017, p. 190) quando afirma que "[...] o comportamento social não pode ser planejado", a questão prática é "como criar condições que tornarão relações socialmente ricas não apenas possíveis, mas também prováveis". A análise da a trajetória das duas escolas nos possibilitou identificar 3 estratégias de semeadura, que combinadas (ou não), possam resultar na disseminação e florescimento de uma semente.

\subsection{A seleção da semente}

Para Manzini (2008), a semente de inovação social não precisa ser, necessariamente, algo novo. Pode ser recombinação e/ou adaptação de ideias já existentes. Compreendemos que uma das capacidades do design é a identificação destas sementes de "ideias promissoras" (FREIRE; DEL GAUDIO; FRANZATO, 2016, p. 642) e a sua transformação "em soluções mais eficazes, atrativas, duradoras e potencialmente replicáveis". (MANZINI, 2017, p. 72). Esta transformação a que Manzini (2017) se refere, principalmente no caso da nossa pesquisa, se configura mais como adaptação do que transformação propriamente dita.

Esta capacidade não é privilégio do designer, mas sim, do conjunto de habilidades humanas que é estimulada por esta metodologia - a criatividade, o senso prático e o senso crítico, sendo que "a integração dos três torna possível imaginar algo que ainda não está disponível, mas que 
poderia estar se as ações apropriadas forem realizadas". (Ibidem p. 45).

Entendemos que o Projeto Ancora identificou a Escola da Ponte como a "ideia promissora", uma semente que poderia ser disseminada. (FREIRE; DEL GAUDIO; FRANZATO, 2016, p. 642). Desta forma os seus princípios e processos fundamentais como as características que podem ser adaptada para ela se inserir e florescer em outro ambiente. A eliminação da estrutura seriada e de turmas fixas, as avaliações em conjunto, a tutoria e a valorização da subjetividade, o estímulo ao diálogo através das rodas de conversa e assembleia são alguns exemplos dessas características, que foram semeadas na Escola projeto Âncora.

Segundo a co-fundadora da Escola Projeto Âncora, Steurer buscou parcerias nas instituições ${ }^{g}$ próximas ao Âncora para pensar numa criar não-tradicional. Como não obteve êxito, resolveu trabalhar com formação de educadores. Os Encontros de Educação ocorriam mensalmente, e contavam com a presença de professores da rede pública, pais e estudantes de pedagogia, visando (re)pensar a educação. A iniciativa durou dois anos, e sempre contava com um convidado especial que possuía uma visão mais ousada da educação. Em um desses encontros o convidado foi o educador José Pacheco.

A escolha da "ideia promissora" (FREIRE; DEL GAUDIO; FRANZATO, 2016, p. 642) é o resultado de uma escolha subjetiva, baseada na cultura e no sistema de valores de quem quer que faça essa escolha (MANZINI, 2017). Os fundadores do Âncora tinham um repertório informal a respeito do assunto, em função das escolas que os rodeavam, das experiências escolares com seus filhos, que frequentaram escolas não-convencionais ${ }^{h}$, e também por organizarem e participarem destes encontros sobre educação. Todo este histórico, assim como sua intenção de construir uma escola diferente para educar as crianças em período integral, impulsionou a identificação de iniciativas que poderiam prosperar.

A combinação destes fatores serviu como uma pesquisa que fundamentou a identificação da "ideia promissora" (FREIRE; DEL GAUDIO; FRANZATO, 2016, p. 642) que, sob a ótica do fundador, mais se adequasse ao Âncora. De fato, "reunir essas iniciativas, torná-las mais acessíveis e apresentá-las [...], consiste em uma atividade que pode ser realizada por qualquer pessoa curiosa e atenta que deseje fazê-lo". (MANZINI, 2017, p. 140). A busca de referências e a sua sistematização são atividades comuns na metodologia do design. Quadros semânticos, contação de história e arquitetura de cenários são apenas três ferramentas do design que possibilitam o mapeamento de ideias e incentivam o diálogo social. Com base nos aportes teóricos, pensamos que com o auxílio de especialista em design ou então, com a capacitação dos atores envolvidos, é possível tornar esta busca mais efetiva e horizontal.

\subsection{Preparação do solo fértil}

Compreendemos que desde o seu surgimento, em 1995, o Projeto Âncora sempre esteve atrelado a promoção do bem-estar social, e a uma mudança na qualidade de vida das pessoas que o frequentavam. A criação de laços com diversos atores (pais de crianças e adolescentes frequentadores da ONG e ministrantes das atividades, administradores da ONG e comunidade em geral, ministrantes das atividades e crianças e adolescentes frequentadores), consequentemente,

\footnotetext{
${ }^{g}$ Nas proximidades do Projeto Âncora existem escolas que possuem metodologias diferentes da tradicional. A escola pública Amorim Lima é inspirada na Escola da Ponte (não possui series, turmas, sala de aula), o colégio Micael possui filosofia Waldorf, entre outras.

${ }^{\mathrm{h}}$ Os filhos dos fundadores frequentaram a escola educação infantil Casa Redonda Centro de Estudos, situada em Carapicuíba - SP. Suas atividades são pautadas no reconhecimento e conhecimento de um modo próprio de ser criança e na presença de uma cultura infantil que afirma o brincar como uma linguagem universal de conhecimento, iniciando o ser humano em sua trajetória de eterno aprendiz. Disponível em:
} <https://criancaenatureza.org.br/content/casa-redonda/>. 
o reconhecimento coletivo do valor da iniciativa como um todo, fomentou o que Manzini (2017) denomina de plataforma habilitante. Essas "são iniciativas capazes de suportar", no sentido de auxiliar o desenvolvimento, "de uma variedade de organizações colaborativas" (MANZINI, 2008, p. 86), servindo como assistência, incubadoras e prestadora de serviços para estas organizações. A infraestrutura da ONG, suas relações com a comunidade, equipe, parceiros e consultores já existentes possibilitaram aos atores envolvidos trabalhar na implementação da Escola de uma forma mais efetiva, tangível e segura.

Em organizações sociais, novas ideias geralmente surgem de um problema ou de uma paixão individual e/ou comunitária. (MULGAN, 2006). Sem dúvida, o A Escola Projeto Âncora surgiu de uma necessidade, e também de um desejo (MANZINI, 2017) dos seus fundadores. A combinação destes dois fatores, juntamente com uma administração competente, porém centralizadora (segundo sua co-fundadora), tornaram viável sua consolidação.

Walter Steurer foi o ator principal para que esta plataforma habilitante se tornasse um terreno fértil para semear a semente de uma escola. Além de ter experiência prática na gestão de negócio e condições financeiras, Steurer foi um conector (MULGAN, 2007) que uniu pessoas, organizações e recursos capazes de criar um "ambiente favorável" (MANZINI, 2017, p. 179) para inovação social. Um ambiente caracterizado como um espaço de tolerância, abertura e promoção do aprendizado. (Ibidem, 2017).

Parece contraditório, mas esta administração hierárquica propiciou a segurança necessária para ousar na implementação da Escola. Entendemos que este não é um fator decisório no desenvolvimento de uma organização, porém dependendo do contexto, acaba sendo uma prerrogativa. Concordamos com Manzini $(2008$, p. 83) quando destaca que "decisões de cima para baixo (top down) e interações entre pares (peer-to-peer) são frequentemente necessárias para ajudar" no surgimento e na permanência de ideias. Embora muitas iniciativas de inovação social se caracterize por uma lógica de baixo para cima (bottom up) sua existência e continuidade exige diferentes tipos de suportes, que podem se originar através da combinação destas relaçõesí.

Para promover a inovação social e gerar valor aos envolvidos, é necessário um novo acordo, em que as pessoas são vistas como sujeitos ativos, sociais e sensíveis capazes de se envolver na produção de um benefício geral. (VINCENT, 2010 apud MANZINI, 2017). A inovação social é um processo que demanda tempo e a sociedade por sua vez acaba, independente de sua vontade, sendo um grande laboratório social. (MANZINI, 2017, p. 180). Enxergamos no design possibilidades para "criar condições para as pessoas se sentirem livres para experimentar coisas novas, e consequentemente, cometer erros". (Ibidem, 2017, p. 179).

Aprender e colaborar são capacidades humanas que podem ser inibidas ou estimuladas. 0 estímulo a estas capacidades pode ser feito através de ferramentas do design, onde, ao projetar uma ideia no papel e prototipá-la, pode ser o início para um exercício de aprendizagem e colaboração, que não onere e inspire os envolvidos na busca de novas soluções. Após a morte do seu fundador a Escola Projeto Âncora tenta trabalhar em uma lógica de gestão horizontal, na qual educadores, educandos, diretoria e familiares se envolvem através de assembleias e rodas de conversa na tomada de decisão.

\subsection{Os jardineiros habilidosos}

José Pacheco é um designer por consequência. Além de ter colocado em prática um modo de fazer educação na década de 1970 em Portugal, o educador mobilizou grupos de pessoas que

\footnotetext{
'A origem da inovação social pode ser de cima para baixo (quando especialistas, tomadores de decisão ou ativistas políticos estão envolvidos), de baixo para cima - quando a maioria envolvida forem civis e oriundos de comunidades) ou híbrida (quando os dois tipos de atores estão envolvidos). (MANZINI, 2014)
} 
se identificaram e colaboraram com as suas ideias, organizando-se para colocá-las em prática. Sua aproximação com a equipe da ONG Projeto Âncora aconteceu em um dos Encontros de Educação. Os fundadores chegaram a convidá-lo para, em conjunto, auxiliá-los a desenvolver a Escola Projeto Âncora, mas na época não foi possível. Somente quatro anos depois desse primeiro encontro, em 2011, pouco antes do falecimento de Walter Steurer, Pacheco entrou em contato e se colocou a disposição, como voluntário, para contribuir com seus conhecimentos para a formação de uma escola dentro da ONG. No início do ano letivo de 2012, a Escola começou a funcionar com a aprovação da Secretaria de Educação do Estado de São Paulo e com boa parte das crianças que frequentavam a ONG Projeto Âncora, matriculadas na Escola Projeto Âncora.

O que Pacheco fez na Escola Projeto Âncora é o que Botero (2013, p. 66 apud MANZINI, 2017, p. 83) chamou provisoriamente de "acompanhamento de parto", quando se refere a criação de uma nova organização, isto é, "a condução e o acompanhamento de aspectos antes, durante e depois, que são necessários para unir esforços comuns em direção a uma variedade de horizontes possíveis". (MANZINI, 2017, p. 83). Percebemos durante as entrevistas' a importância da credibilidade da figura do educador para a equipe e para os fundadores. Pacheco não foi apenas um "norteador", mas também uma pessoa que inspirava e avalizava as ações em prol da construção. Uma referência de alguém que já havia participado de um processo de mudança na educação, que embora não falasse especificamente o que deveria ser feito, era uma fonte muito rica de troca.

Observamos que o educador não tinha a intenção de seguir ou propor receita. Em suas próprias palavras, ao descrever o processo de formação da Escola da Ponte, Pacheco (2008) afirma que não havia modelos, mas referências que podiam ser colhidas de diversos projetos. Por entender que o desenvolvimento de um projeto como este é um "ato coletivo" (Ibidem, p. 14), acreditava que a melhor forma de auxiliar sua viabilização era capacitando os educadores a terem suas próprias interrogações e respostas. Em outras palavras, Pacheco não impôs o que devia ser feito, mas estimulou a capacidade dialógica dos envolvidos, com rodas de conversa e exercício prático, para fazer as coisas acontecerem. (MANZINI, 2014).

\section{Considerações Finais}

A Escola Projeto Âncora é um espaço provido de significado para um grande número de pessoas - sejam elas representantes da comunidade, educadores, ou então, entusiastas que admiram ou questionam o seu modo de fazer educação. Ao definirmos a relação entre Escola da Ponte e a Escola Projeto Âncora como nosso objeto de pesquisa, vislumbramos a possibilidade concreta em aproximar os aportes teóricos do design estratégico, assim como o nosso olhar de designer, ao ambiente educacional. Enxergamos na relação entre as duas escolas uma forma de disseminação orgânica e generativa de boas ideias que podem gerar inovação social e mudar comportamentos em prol do bem-estar coletivo.

Entendemos que o design pode contribuir na criação e desenvolvimento de estratégias de semeaduras através de sua lógica de processos, juntamente com suas ferramentas de pesquisa e visualização para auxiliar a identificação de uma ideia, e por meio da sua cultura de projeto (ideação, prototipação) possibilitando a compreensão e alinhamentos de propósitos e posicionamentos.

\footnotetext{
j Durante a nossa imersão, no mês de agosto de 2017, na Escola Projeto Âncora entrevistamos cinco pessoas que participaram do seu desenvolvimento inicial, à luz da filosofia da Escola da Ponte: Regina Steurer (co-fundadora da Escola Projeto Âncora), Cláudia Santos e Edilene Brito (educadoras e coordenadoras pedagógica), Vitor Lacerda (educador) e Suzana Ribeiro (educadora e coordenadora geral). O professor educador José Pacheco, (fundador da Escola da Ponte e co-fundador da Escola Projeto Âncora) respondeu nossos questionamentos por e-mail.
} 
As estratégias descritas e analisadas, sob nossa perspectiva, tornaram possível a semeadura da semente (filosofia e cultura) da Escola da Ponte, na ONG Projeto Âncora, fazendo florescer a Escola Projeto Âncora. Isto não significa, porém, que a combinação destas três estratégias em outro contexto possibilite o mesmo resultado. A ideia de uma semente depende muito do ambiente em que ela será semeada, considerando não apenas o lugar, mas também a abertura das relações sociais e do comportamento do grupo que a quer semear. É justamente no âmbito da aceitação de uma nova ideia que reside a mudança de comportamento e, consequentemente, a inovação social.

\section{Referências}

ALVES, R. A escola com que sempre sonhei sem imaginar que pudesse existir. 13a ed. Campinas, SP: Papirus, 2012.

BOURDIEU, P.; PASSERON, JC. A reprodução: elementos para uma teoria do sistema de ensino. Tradução de Reynaldo Bairão. 70 ed. Petrópolis: Vozes, 2014.

CASTELLS, M. A sociedade em rede. São Paulo: Paz e Terra, 2009.

FRANZATO, C. et al. Inovação Cultural e Social: design estratégico e ecossistemas criativos. In: FREIRE, K. (org.). Design Estratégico para a Inovação Cultural e Social. São Paulo: Kazuá, 2015.

FREIRE, P. Pedagogia do Oprimido. 17ạ ed. Rio de Janeiro: Paz e Terra. 1987

FOUCAULT, M. Vigiar e Punir: nascimento da prisão. Tradução de Raquel Ramalhete. 38o ed. Petrópolis, RJ: Editora Vozes, 2010.

LÉVY, P. A inteligência coletiva: para uma antropologia do ciberespaço. São Paulo: Edições Loyola, 2011.

MANZINI, E Design para a inovação social e sustentabilidade - Comunidades criativas, organizações colaborativas e novas redes projetuais. Coordenação de tradução Carla Cipolla; equipe Elisa Spampinato, Aline Lys Silva. Rio de Janeiro: E-papers, 2008.

. Making Things Happen: Social Innovation and Design. Design Issues, v.30 n.1, 2014.

Design. Quando todos fazem design: uma introdução aao design para inovação social. Trad. Luzia Araújo. São Leopoldo: Ed. UNISINOS, 2017.

MERONI, Anna. Strategic design: where are we now? Reflection around the foundations of a recent discipline. Strategic Design Research Journal, v.1, n.1, Dec 1, p.31-38, 2008.

MULGAN, G. Social innovation: what is it, why it matters and how it can be accelerated. London: Young Foundation, 2006

.Design in public and social innovation - what works, and what could work better, 2014.

MURRAY, R., CAULIER-GRICE, J., and MULGAN, G. The open book of social innovation. London: Young Foundation, NESTA, 2010.

ORLANDI, E. Análise do discurso: princípios e procedimentos. São Paulo: Pontes, 2007.

PACHECO, J. Escola da Ponte: formação e transformação da educação. Petrópolis, RJ: Vozes, 2008. 